Article

\title{
An Estimation Model with Generalization Characteristics for the Internal Impedance of the Rechargeable Batteries by Means of Dual ANN Model
}

\author{
Minella Bezha *, Ryo Gondo and Naoto Nagaoka \\ Doshisha University, Graduate School of Science and Engineering, Department of Electrical and Electronic, \\ Engineering Power System Analysis Laboratory, 1-3 Tatara Miyakodani, Kyoto 610-0394, Japan; \\ gryo0412@gmail.com (R.G.); nnagaoka@mail.doshisha.ac.jp (N.N.) \\ * Correspondence: cyjc2301@mail4.doshisha.ac.jp; Tel.: +81-70-4406-9691
}

Received: 10 January 2019; Accepted: 4 March 2019; Published: 12 March 2019

\begin{abstract}
An estimation method of equivalent circuit parameters for rechargeable batteries that follows Artificial Neural Network (ANN) logic is proposed in this paper. The capability of the nonlinear analysis of the ANN is suitable for estimating the parameters that are nonlinearly involved in the complex circuit equation. The parameters have to be obtained from the complex internal impedances, which are measured in a wide frequency range. The accuracy is improved by dividing this wide range into a low-frequency and a high-frequency region. These regions are strongly related to the capacity fade and the maximum chargeable/dischargeable current, respectively. The improved method will determine the optimal frequency region for three different rechargeable batteries, which are composed of $\mathrm{Li}-\mathrm{Ion}, \mathrm{Pb}$ and $\mathrm{Ni}-\mathrm{MH}$. The accuracy of the proposed method is confirmed by a comparison with the measured results obtained using a conventional frequency domain method. For obtaining the real-time diagnostics of the battery, an improved dual ANN system, which employs unequal sampling, is proposed to obtain the circuit parameters. The deterioration of a battery can be detected from the estimated parameters, which can help in further investigations that aim to develop diagnostic models for the embedded circuit in industrial applications.
\end{abstract}

Keywords: optimal frequency region; dual ANN; parameter estimation; rechargeable battery; internal impedance; EV

\section{Introduction}

The technology of portable energy storage is rapidly improving due to the need for high-energy capacity and fast charging capabilities. This is further compounded by the desire for smart and autonomous devices. In all battery systems from the small portable devices to large-scale storage systems, achieving improvements in the battery manufacturing technology is the main goal for high technology battery companies and electric vehicle manufacturers. For mobile computer manufacturers, the operating time is still the weak point while the chips and operating systems are becoming more efficient in terms of saving power. The dynamic characteristic of the battery, i.e., the operational characteristics of the battery driven equipment, is closely related to the State of Charge $(\mathrm{SoC})$ and the maximum chargeable/dischargeable current. This is because the maximum battery current is limited by the terminal voltage, which depends on and is related to the SoC and the internal impedance of the battery. As explained and confirmed in [1,2], the internal impedance can be expressed by a resistor, which expresses the voltage drop in a high frequency region, and some RC parallel circuits, which expresses the transient characteristics of the battery. On the other hand, the battery health is a key factor in improving and advancing new technologies. An accurate lifetime estimation and diagnosis 
of deterioration becomes an important task in order to increase the battery capacity. The internal impedance is known as an index of the battery deterioration. It is necessary to develop a diagnostic system, which can operate without removing the battery so as to maintain the normal operation of the processes. The aging of the rechargeable batteries is a concern, especially when they are used for applications that could potentially have long-life usage. The battery can only efficiently operate inside its safety zone when there is a practical and accurate diagnosis system [3]. An estimation method for the internal impedance, which is one of the key variables determining the battery deterioration, has been proposed based on the circuit theory, with different approaches having been undertaken to estimate the internal impedance or to relate factors that contribute to the battery deterioration as explained in [1-6]. The computational time and memory requirements of the on-board diagnostic system are points that need to be improved. This research introduces an improved parameter estimation method based on Artificial Neural Network (ANN) logic. The battery terminal voltage and the load current waveform are used for the estimation of the parameters. By dividing the frequency characteristic into two regions, an accurate evaluation of the maximum current and the capacity fade of the battery can be estimated. The deterioration level and discharging rate was increased for a better generalization algorithm.

\section{Battery Modelling}

Rechargeable batteries are crucial for the technological advancement when it comes to autonomous systems and devices. Different types of an equivalent circuit model (ECM) have been proposed by the researchers, which helps us to understand and explain the chemical composition or electrochemical reaction of the rechargeable batteries. These circuits have different degrees of complexity and nonlinearity, which can express different behaviors. The response is different because it is highly dependent on the type of the rechargeable battery.

\subsection{Battery Equivalent Circuits}

When choosing a specific model, the following characteristics of the model must be taken into consideration. It is first important whether this model can explain precisely the battery behavior, including the DC and transient characteristics. Secondly, there must be a trade-off between performance/cost, which includes variables, such as accuracy, complexity of the proposed model, experimental and computational time, in order to provide a total cost in the end. In general, these models can be divided into three main groups:

- Electrochemical models,

- Mathematical models,

- Electric equivalent circuit models.

Despite the fact that the electrochemical model can accurately explain the operational characteristics of the battery, these models unfortunately have high complexity. This introduces new problems and requires a long computational time for calculations [7-9].

Mathematical models are based on the derived equations from the data retrieved through experiments. The high grade of the equations and nonlinear behavior of the battery makes these models unable to fully explain and estimate the variables and the phenomenon, which happens during operation $[10,11]$. Electric equivalent circuit models are very suitable for the purpose of real-time estimation due to their simplified mathematical and numerical approach. Many types of the equivalent circuit have been proposed and each are suitable for a specific purpose, such as studying the DC or transient characteristics as explained in $[5,6]$.

Several examples of the equivalent circuit of a battery are shown in Figure $1 \mathrm{a}-\mathrm{c}$, based on their scale of complexity. Figure 1a illustrates the simplest model that is composed of a resistor and an internal voltage source. Although the model can explain and shows satisfactory accuracy in calculating the DC characteristic, it cannot express the operational characteristic during the dynamic process, i.e., the transient behavior of the battery. Figure $1 \mathrm{~b}$ shows a more complex equivalent circuit of 
the battery. The impedance of the model that consists of a series resistor $R_{\mathrm{B} 0}$ with an $R C$ parallel circuit $\left(R_{\mathrm{B} 1}\right.$ and $\left.C_{\mathrm{B} 1}\right)$ can be written by the first order rational function. Figure $1 \mathrm{c}$ illustrates a more sophisticated model that is expressed by a high-order rational function. Although the accuracy of the model increases with an increase in the number of $R C$ circuits, the estimation of the parameters becomes difficult. The internal voltage in each model $V_{0}$ expresses an open-circuit voltage (OCV) of the battery. In general, the OCV is determined by its SoC and it shows only small changes in its value due to the deterioration effect.

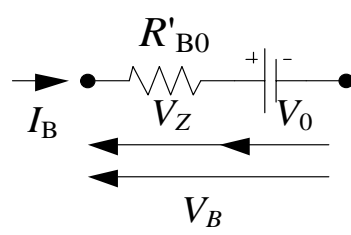

(a)

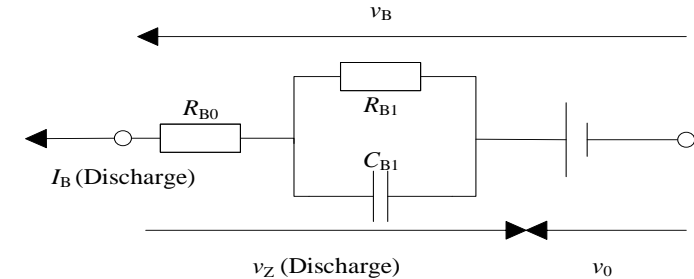

(b)

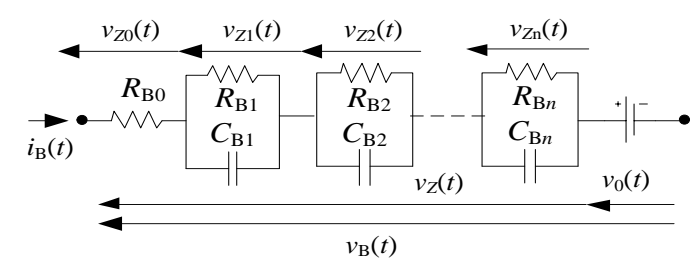

(c)

Figure 1. (a) Simplest conventional model. (b) First order model. (c) High order model.

\subsection{Conventional Modelling}

Different methods and approaches which estimate the deterioration of the batteries have been proposed. Despite the fact that frequency characteristics of the internal impedance can be accurately measured based on the AC superimposition method, still it requires a removal of the battery, especially for dynamic systems like EV, HEV, PHEV [12]. This method cannot be used during operation as an online process. The frequency characteristics can be obtained from the battery voltage and current waveforms by substituting the steady measurement with discrete Laplace Transform (DLT)) [13-15]. Although this method is applicable for diagnosis during operation, still requires a long computational time in order to obtain the characteristics at a wide frequency range. Different proposed methods are based on a logarithmic segmented Laplace Transformation as already confirmed and explained in [9], as well explained in exponential \& logarithmic Fourier transformation applications in $[16,17]$. This method makes possible to study the wideband characteristics. This algorithm simplifies and reduce the complexity level, also a low-cost diagnostic system can be realized. However, it needs to secure the numerical stability.

Figure 2 Shows a measured voltage characteristic of a Li-Ion battery during CCCV charging mode. It corresponds with the OCV-SoC plot.

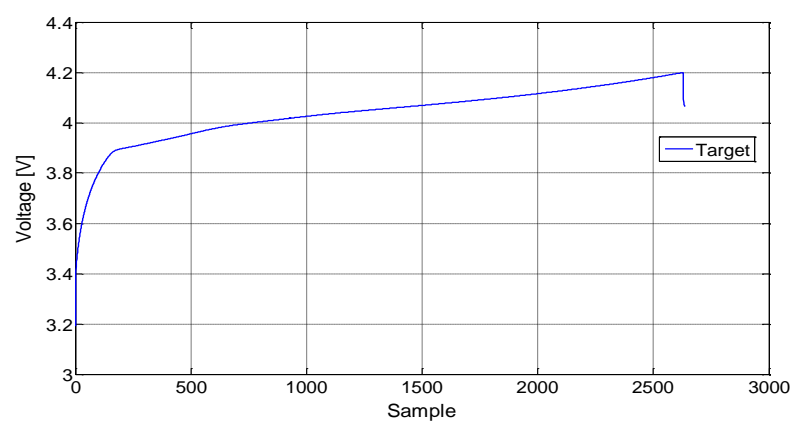

Figure 2. Voltage characteristics of a Li-Ion battery during charging (ICR18650PD, 1 sample/s). 


\subsection{Proposed Model}

The ECM applied in this paper is shown in Figure 3. It is provided by a modification of the electric equivalent circuit shown in Figure 1c. This ECM consists of the second order circuit with the capacitor $C_{\infty}$ connected in series. The invers of the capacitance corresponds to the slope of the voltage shown in Figure 2. The need to insert this capacitor is also clarified to explain the dynamic characteristic from the experimental results. The series capacitor expresses the characteristic of the battery in a low frequency region. For example, it explains the changing speed. In addition, the capacity fade can be detected by the capacitance $C_{\infty}$. Figure 4 shows an example of a capacity fade of a Ni-MH battery cell.

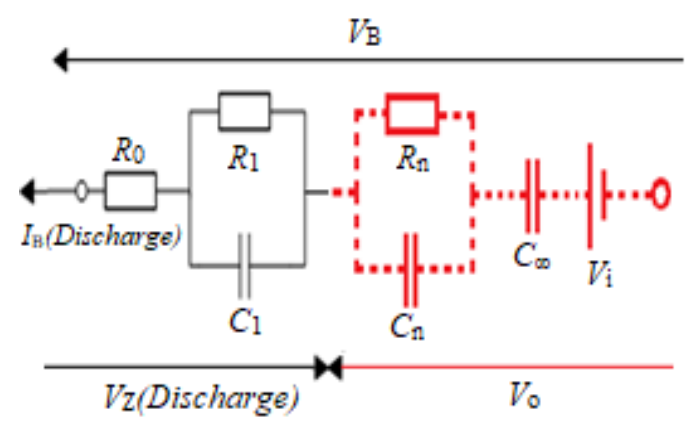

Figure 3. Proposed equivalent model.

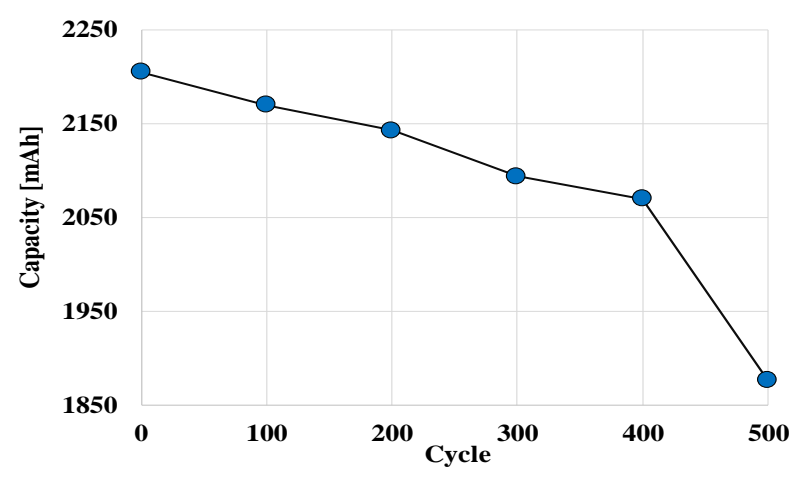

Figure 4. Capacity fade vs. number of charging/discharging cycles.

\section{Experiment and Estimated Results}

\subsection{Diagnostic Approach by the Proposed Circuit}

The composition of the proposed diagnosis method is based on two steps. First, the hardware is developed to obtain the experimental data, which will be used for the training model of ANN. In the second step, this ANN is used in order to estimate the desired characteristics.

Figure 5 shows the block diagram of the developed circuit in order to obtain the required experimental data for the training process of the ANN. The circuit is based on that described in [18], which can charge and discharge $\mathrm{Pb}, \mathrm{Ni}-\mathrm{MH}$ or Li-Ion battery by an arbitrary current waveform. In addition, the measured voltage and current waveforms are saved to an SD-card. 


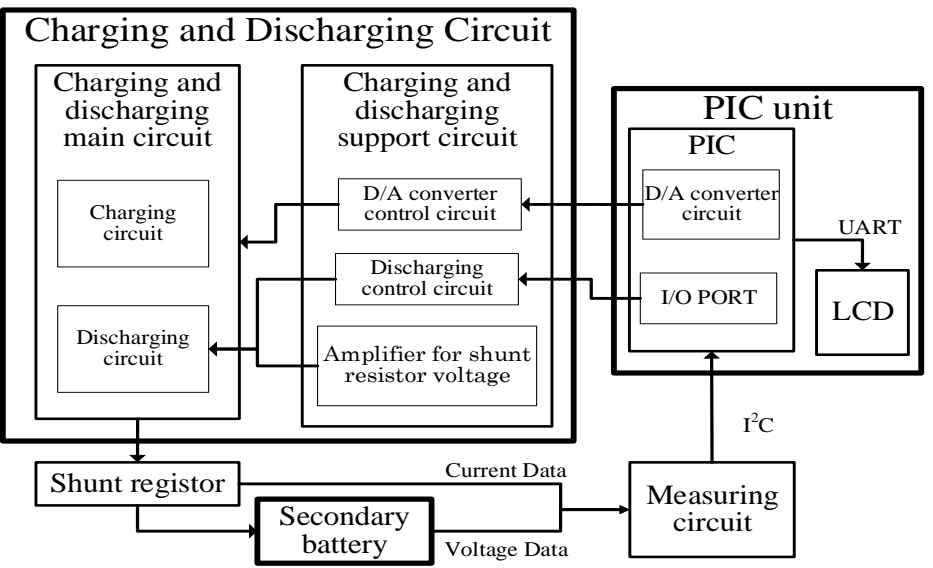

Figure 5. Logic diagram of proposed circuit for charging/discharging battery.

\subsection{Experimental Data from Different Batteries}

This section explains the experimental data obtained by the developed circuit. From the comparisons of the characteristics and estimated values between the different types of batteries, the credibility and accuracy of the proposed method can be confirmed. The Li-Ion battery shows many advantages compared to the other types of batteries. Figures 6 and 7 show the characteristics of the Li-Ion cell battery.

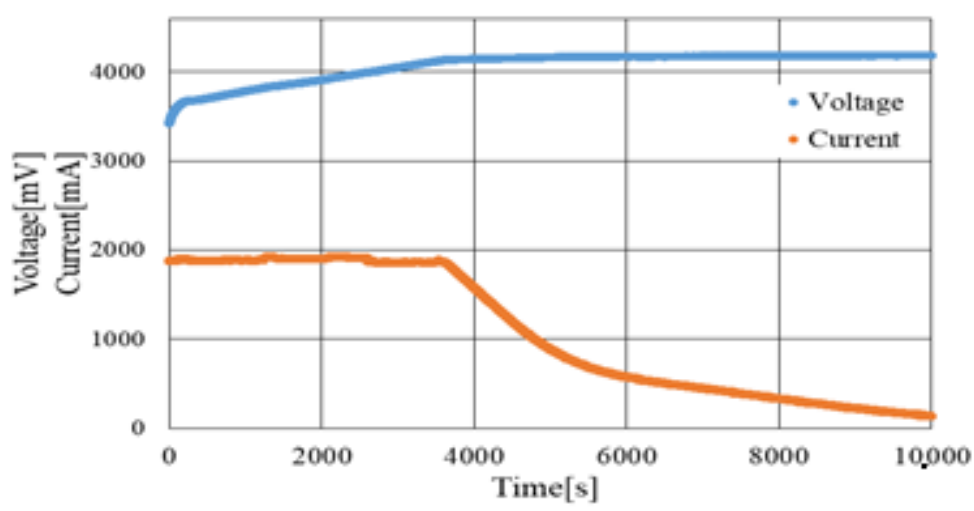

Figure 6. Charging characteristic of Li-Ion during CCCV mode.

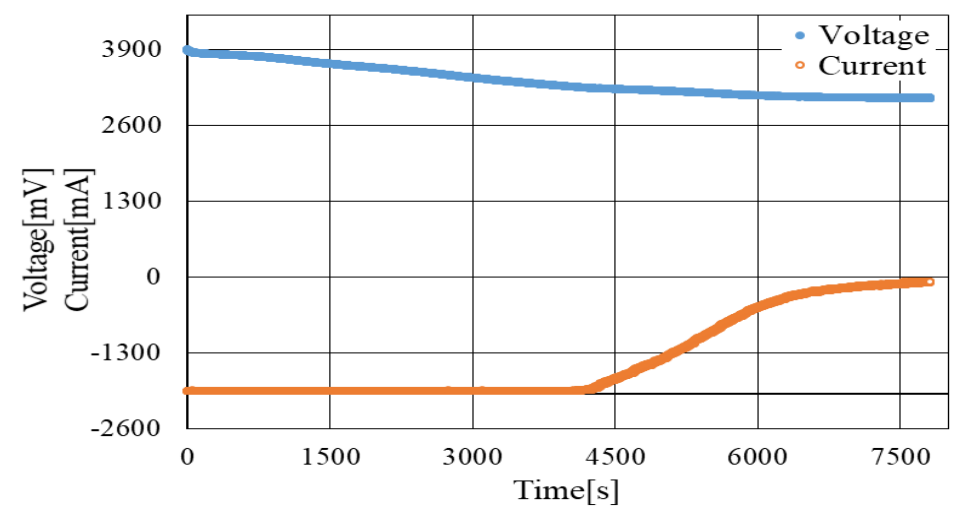

Figure 7. Discharging characteristic of Li-Ion during CCCV mode.

Table 1 shows the main specifications for the Li-Ion battery used in this study, cylindrical single cell 18650. 
Table 1. Primary Specifications of Li-Ion cell.

\begin{tabular}{cc}
\hline Model & ICR18650PD \\
\hline Diameter $^{1}$ & $18.3 \mathrm{~s} \pm 0.2$ \\
Height $^{1}$ & $64.95+0.15 /-0.30$ \\
Weight $^{2}(\mathrm{~g})$ & 46 \\
Max. voltage $^{3}(\mathrm{~V})$ & 4.2 \\
${\text { Max. } \text { current }^{3}(\mathrm{~A})}_{\text {End voltage }^{4}(\mathrm{~V})}$ & 2.25 \\
Max. current $^{4}(\mathrm{~A})$ & 2.75 \\
Nominal voltage $(\mathrm{V})^{\text {Minimum capacity }(\mathrm{mAh})}$ & 6 \\
Type & 3.7 \\
\hline
\end{tabular}

${ }^{1}$ Dimensions of fresh cell without tube, ${ }^{2}$ Approximate values. ${ }^{3}$ Charge (CCCV), ${ }^{4}$ Discharge (CC).

The experiments conducted in this study were made at $25^{\circ} \mathrm{C}$ as a constant ambient temperature, during the practical test in order to obtain the actual data. It must be clear that this method is not based on temperature-compensated model like $[19,20]$, due to constant temperature at $25{ }^{\circ} \mathrm{C}$, but also a very limited info regarding $30^{\circ} \mathrm{C}$ was inserted in the ANN database. The Ni-MH battery chemistry is a hybrid of the proven positive electrode of the sealed Ni-Cd battery with the energy storage features of metal alloys based on development for advanced hydrogen energy-storage concepts. Regarding this battery characteristics it introduces few. Its discharge voltage profile is relatively flat, has several hundred of cycles regarding the recharge capability. Efficient at high rate discharges. $\mathrm{Ni}-\mathrm{MH}$ retains $50-80 \%$ self-discharge rate within 12 months. Operates well at a wide range of temperatures. When it comes to weight it's lighter than Lithium batteries as well can be recycles for a better environmental-friendly effect. Table 2 shows the specification for the Ni-MH used in this study.

Table 2. Primary Specifications of Ni-MH Panasonic-BSG cell.

\begin{tabular}{cc}
\hline Model & HHR-380A \\
\hline Diameter & 17 \\
Height & 67 \\
Weight (g) & 53.52 \\
Nominal voltage (V) & 1.2 \\
Discharge Rate (mA) & 740 \\
Standard Charge Current (mA) & 370 \\
Rated capacity (mAh) & 3700 \\
\hline
\end{tabular}

Figures 8 and 9 shows the characteristics of a Ni-MH battery obtained by the CCCV charging and discharging, respectively. In the experiments, two Ni-MH batteries are connected in series, because the voltage across the cell is lower than the voltage specification of the developed circuit. The rated capacity of each battery is 3.7Ah and is charged/discharged by a current rate of $0.2 \mathrm{C}, 0.5 \mathrm{C}, 1 \mathrm{C}$.

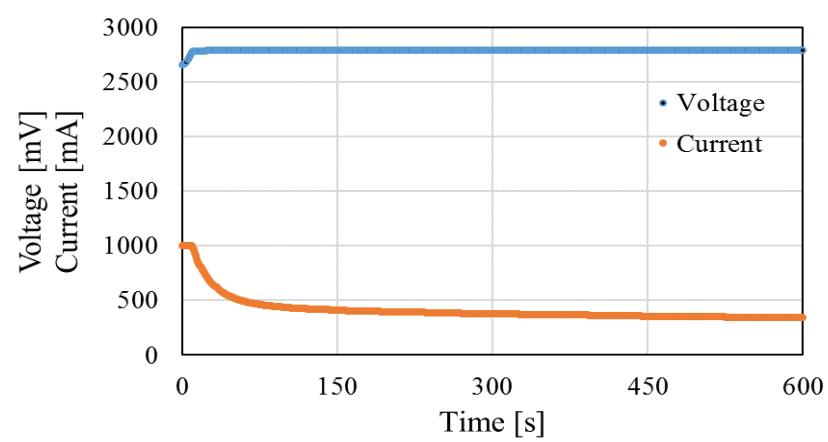

Figure 8. Charging characteristic of Ni-MH 2 cell in series during CCCV mode. 


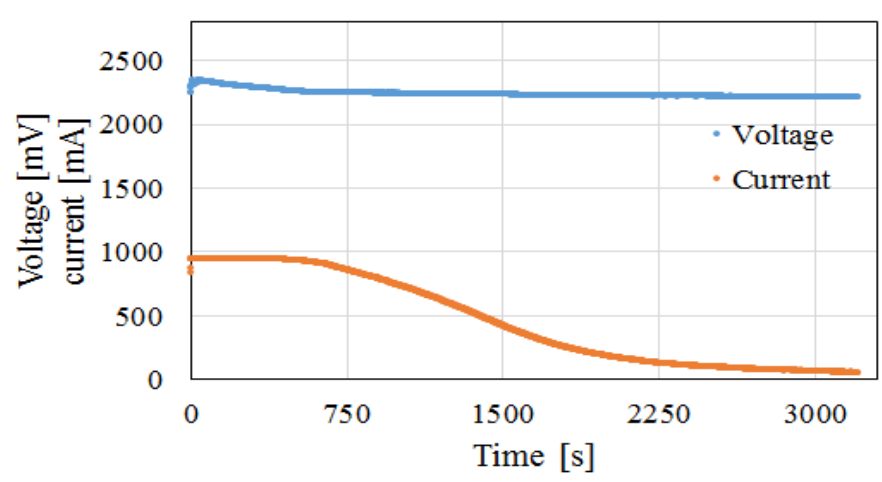

Figure 9. Discharging characteristic of Ni-MH 2 cell in series during CCCV mode.

Lead-acid battery known as $\mathrm{Pb}$ battery is the most common rechargeable battery. Despite having a very low energy-to-weight ratio and a low energy-to-volume ratio, its ability to supply high surge currents means that the cell has a relatively large power-to-weight ratio. This battery has few advantages and drawbacks. Despite the drawbacks, still Pb batteries are very used in low budget projects or in initial low-cost situation investment. The chemical composition of $\mathrm{Pb}$ batteries is well known to be very complex compared with other commercial battery technologies. With the new Japanese $\mathrm{Pb}$ batteries technology by Hitachi Ltd. (Tokyo, Japan), producing with Pure Lead, Punching Carbon technology (PPC), which have improved the capacity, discharging rate, lifetime and environmental applicability. But in this study a common $\mathrm{Pb}$ battery was used, without the cutting-edge technique of PPC, Table 3 shows the specifications. During the experiment, a deep-cycle type $\mathrm{Pb}$ battery was used. Figures 10 and 11 show the $\mathrm{Pb}$ characteristics during charging/discharging.

Table 3. Primary Specifications of the valve-regulated lead-acid battery.

\begin{tabular}{cc}
\hline Model of Product & NP3-6 \\
\hline 20-h Rated Capacity & $3.0 \mathrm{Ah}$ \\
Nominal Voltage & $6 \mathrm{~V}$ \\
Maximum Charging Current & $0.25 \mathrm{C}_{20}(=0.75 \mathrm{~A})$ \\
Maximum Discharging Current & $3 \mathrm{C}_{20}(=9 \mathrm{~A})$ \\
Temperature Range & -15 to $40^{\circ} \mathrm{C}$ \\
\hline & $5.25 \mathrm{~V}\left(\right.$ under $\left.0.2 \mathrm{C}_{20}\right)$ \\
Cutoff Discharging Current & $5.10 \mathrm{~V}\left(0.2 \mathrm{C}_{20}\right.$ to $\left.0.5 \mathrm{C}_{20}\right)$ \\
& $4.65 \mathrm{~V}\left(0.5 \mathrm{C}_{20}\right.$ to $\left.1.0 \mathrm{C}_{20}\right)$ \\
& $3.90 \mathrm{~V}\left(\right.$ over $\left.1.0 \mathrm{C}_{20}\right)$ \\
\hline
\end{tabular}

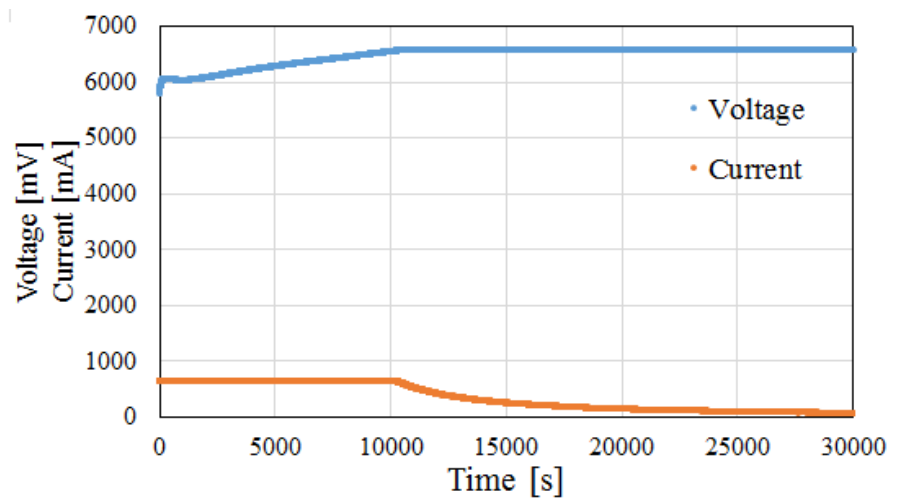

Figure 10. Characteristic of $\mathrm{Pb}$ battery during $\mathrm{CCCV}$ charging mode. 


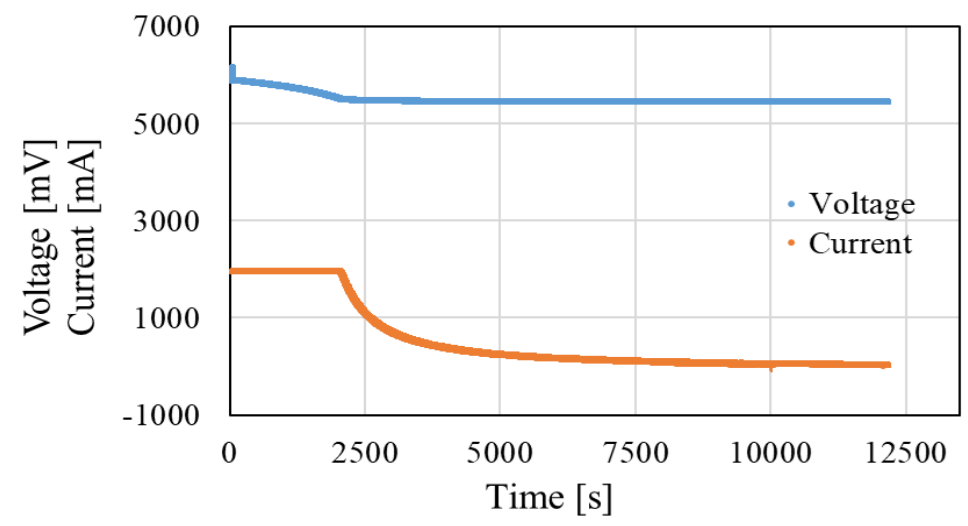

Figure 11. Characteristic of $\mathrm{Pb}$ battery during $\mathrm{CCCV}$ discharging mode.

\subsection{Sampling Method}

As already mentioned in the previous section, the proposed method divides the estimation region into two frequency regions. The regions can be specified in a time domain that uses the ANN as its input signal. The conditions are:

$$
\Delta t_{1} \leq \frac{1}{2 f_{\max }}, \quad T_{2} \geq \frac{1}{f_{\min }}
$$

where $\Delta t_{1}$ represents the time step of the first (high) frequency region, $T_{2}$ is the maximum observation time of the second (low) region, $f_{\max }$ is the maximum observation frequency and $f_{\min }$ is the minimum frequency resolution. The sampling method is based on the results from Equation (2). The number of the samples for each region is composed based on the following equation:

$$
N_{k}=\frac{1}{N_{\text {reg }}} 2^{2 \log _{10} \frac{f \max }{f_{\min }}+\varepsilon}, \quad \varepsilon \geq 2
$$

where $N_{k}$ is the number of samples of the $k$-th section, $N_{\text {reg }}(=2)$ is the number of regions and $\varepsilon$ is the overlap coefficient. During the high frequency region, the sampling time was constant with the same $\Delta t$. Furthermore, in the low frequency region, the sampling time was constant in order to maintain the same characteristics.

Figure 12 explains the relation between the equivalent circuit and the electrochemical meaning of the internal impedance using the Cole-Cole plot. The parameters $R_{0}, R_{1}$ and $C_{1}$ are obtained through the high frequency sampling mode. The other parameters obtained through the low frequency sampling mode explain the transient characteristic of the kinetically controlled region, which is closely related to the $\mathrm{SOH}$. Figure 13 shows the typical frequency borders. Point $\mathrm{A}$ is positioned with the frequency of $1 \mathrm{MHz}$ and is related to electronic conductivity, Point $\mathrm{B}$ at $1 \mathrm{kHz}$ is obtained through the SEI film and Point $\mathrm{C}$ at $10 \mathrm{~Hz}$ is related to the charge transfer at the electrode/electrolyte interface. Point $\mathrm{D}$ at $10 \mathrm{mHz}$ expresses the diffusion in the electrode and electrolyte phase. The lowest frequency region Point $\mathrm{E}$ occurs at $1 \mathrm{mHz}$, which has a state of charge that changes during the impedance measurement.

A main focus for this study involves finding the optimal frequency regions (OFR) in order to explain and estimate the deterioration of the batteries based on the values of the ECM parameters. From one battery type to another one, the best OFR will be different. Li-Ion is a high-performance energy battery with very low memory effect and long last cycle performance. In contrast, Ni-MH is affected by the memory effect and will approximately lose up to $35 \%$ of their stored energy in 3 months (up to $40 \%$ for Ni-Cd battery). Compared with the lead acid battery, it self-discharges the same amount in one year. Table 4 shows the regions with a specific frequency range. Table 5 shows the proposed combinations for a further accurate investigation in order to be used for the proposed estimation method. In the low and high frequency regions, the starting value was maintained to be constant before proceeding by 1 decade for each case. The authors of this present study are aware 
that the combinations are infinitive but this study wants to maintain a possible and actual scenario for measurements and simultaneously simplify the dividing range.

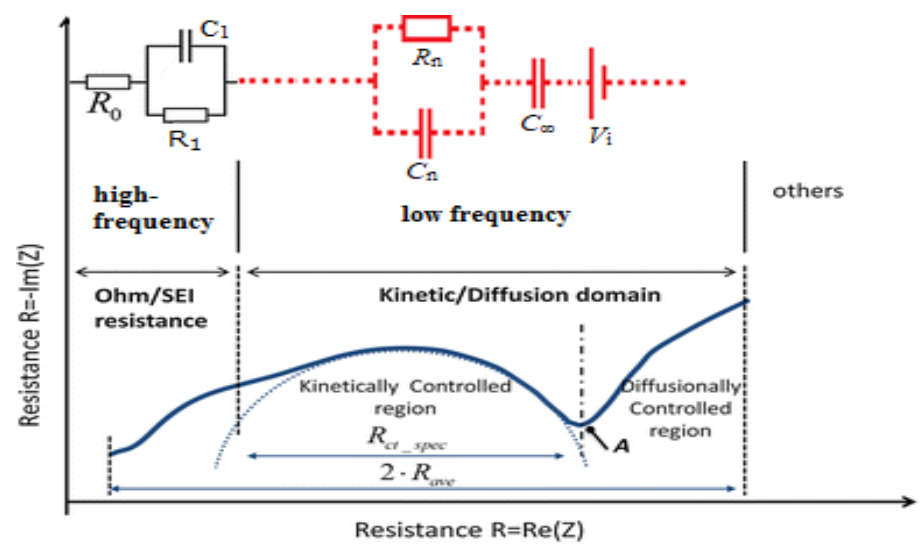

Figure 12. Relation of variables in the frequency response with a physical meaning.

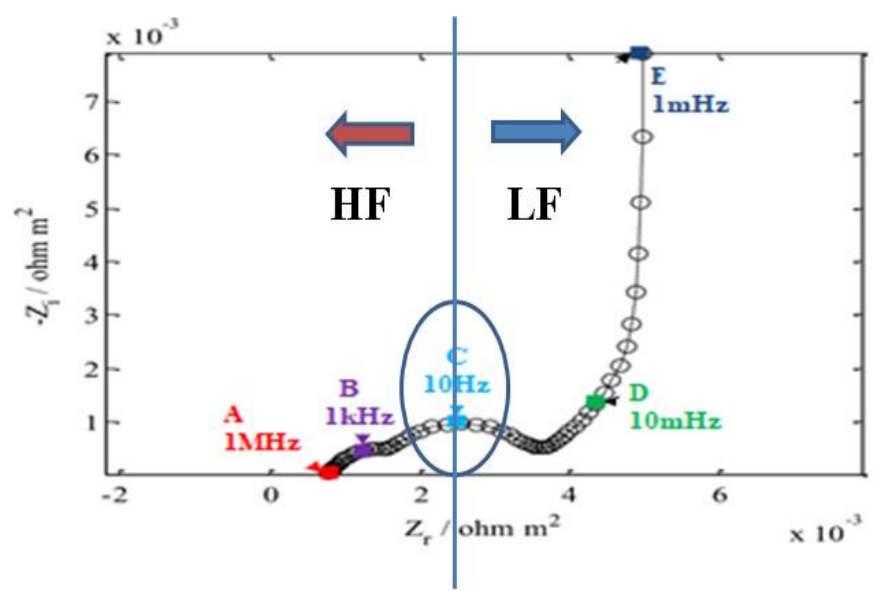

Figure 13. Cole-Cole plot impedance characteristics through the frequency spectroscopy.

Table 4. Frequency of regions.

\begin{tabular}{cc}
\hline Low Freq. & High Freq. \\
\hline $10 \mathrm{mHz}-100 \mathrm{mHz}$ & $10 \mathrm{~Hz}-100 \mathrm{~Hz}$ \\
$10 \mathrm{mHz}-1 \mathrm{~Hz}$ & $10 \mathrm{~Hz}-1 \mathrm{kHz}$ \\
$10 \mathrm{mHz}-10 \mathrm{~Hz}$ & $10 \mathrm{~Hz}-10 \mathrm{kHz}$ \\
\hline
\end{tabular}

Table 5. Proposed combinations.

\begin{tabular}{ccc}
\hline Cases & Low Freq. & High Freq. \\
\hline Case 1 & $10 \mathrm{mHz}-100 \mathrm{mHz}$ & $10 \mathrm{~Hz}-100 \mathrm{~Hz}$ \\
Case 2 & $10 \mathrm{mHz}-100 \mathrm{mHz}$ & $10 \mathrm{~Hz}-1 \mathrm{kHz}$ \\
Case 3 & $10 \mathrm{mHz}-100 \mathrm{mHz}$ & $10 \mathrm{~Hz}-10 \mathrm{kHz}$ \\
Case 4 & $10 \mathrm{mHz}-1 \mathrm{~Hz}$ & $10 \mathrm{~Hz}-100 \mathrm{~Hz}$ \\
Case 5 & $10 \mathrm{mHz}-1 \mathrm{~Hz}$ & $10 \mathrm{~Hz}-1 \mathrm{kHz}$ \\
Case 6 & $10 \mathrm{mHz}-1 \mathrm{~Hz}$ & $10 \mathrm{~Hz}-10 \mathrm{kHz}$ \\
Case 7 & $10 \mathrm{mHz}-10 \mathrm{~Hz}$ & $10 \mathrm{~Hz}-100 \mathrm{~Hz}$ \\
Case 8 & $10 \mathrm{mHz}-10 \mathrm{~Hz}$ & $10 \mathrm{~Hz}-1 \mathrm{kHz}$ \\
Case 9 & $10 \mathrm{mHz}-10 \mathrm{~Hz}$ & $10 \mathrm{~Hz}-10 \mathrm{kHz}$ \\
\hline
\end{tabular}

In each case, depending on the battery type, we will show and will try to explain which case is more appropriate to use in order to reduce the point of frequency for an optimal calculation 
time/accuracy rate. In the previous study, the low and high frequency regions were wide in order to explain the physical meaning of each variables for the proposed ECM. However, the most efficient region will be investigated in this study.

\section{Artificial Neural Network}

\subsection{Designing the Optimal Structure}

ANN logic is an ML approach based on the human brain behavior, which is an electronic imitation of the neural structure of the brain in other words. This method is based on processes, learning, validation and test. The proposed ANN method is processed in MATLAB R2018a and in this study, the hardware specifications of the used PC are shown in Table 6.

Table 6. Hardware Specifications.

\begin{tabular}{ccc}
\hline CPU & RAM & HDD \\
\hline i7 $67003.4 \mathrm{GHz} / \mathrm{L} 3$ cache $8 \mathrm{Mb}$ & $8 \mathrm{~Gb}$ DDDR4/2133 MHz & $1 \mathrm{~Tb}$ \\
\hline
\end{tabular}

During the training process that is the first step, the selection of the most appropriate NN configuration is crucial. The typical structure of the ANN is composed of an input layer, a hidden layer and an output layer. The input signals are multiplied by the weights before being calculated through the mathematical function, which expresses the activation of the neuron. The next necessary step of the process is to compute the output of the neuron. A higher weight of the artificial neuron expresses a strong relation with the input. It expresses that the specific input is more significant. The neuron is inhibited by the negative weight. Depending on the weights, the state of the neuron will be changed. The output is optimized by adjusting the weights of an artificial neuron according to the specific inputs, i.e., by learning with a "teacher." This is the main role of the ANN in the training phase for finding an algorithm in order to obtain the desired output from the NN automatically. The relation between the input and output is shown in Equation (3):

$$
a=\sum_{i=1}^{R} W_{i j} p_{i}+b_{i}
$$

where $W_{i j}$ is the weight, $p$ is the input and $a$ is the output. As explained in [20-24], the weight between the $i$ th neuron of the $(k-1)$ th layer and the $i$ th neuron of the $k$ th layer is defined as $W_{i j}, k$. in order to define the most appropriate adapted values:

$$
W_{i j}, k\left(t_{n}\right)=W_{i j}, k\left(t_{n-1}\right)-\frac{\alpha E\left(t_{n}\right)}{W_{i j}, k\left(t_{n-1}\right)} \Delta W_{i j}, k\left(t_{n-1}\right)
$$

where $0<\alpha<1$ and $E=1 / 2 \sum\left(y_{i}-b_{i}\right)^{2}, i=1 \ldots n, y_{i}$ is $i$ th actual output and $b_{i}$ is $i$ th simulation output.

In addition to this, the time series prediction approach is applied for the Linear Prediction Error Methods (L-PEM), which can be applied to different arbitrary model parameterizations. One of the positive things of this method is that it can be applied to a wide region of model parameterizations. Based on the previous samples as in the case of $x(t-\Delta t), x(t-2 \Delta t), \ldots, x(t-k \Delta t)$, the value of $x(t)$ needs to be predicted. The required value can be expressed as a function of the previous $k$ samples:

$$
\begin{gathered}
\bar{X}(t \mid t-\Delta t, \cdots, t-k \Delta t)=\Phi(x(t-\Delta t), \cdots, x(t-k \Delta t)) \\
\bar{X}(t \mid t-\Delta t, \cdots, t-k \Delta t)=\sum_{i=1}^{k} \theta_{i} x(t-i \Delta t)
\end{gathered}
$$


In Equation (5), the left side of the equation expresses the one-step-ahead prediction of the output and $\Phi$ is an arbitrary function of the past-observed data. If the function $\Phi$ is linear, the prediction is called a linear PEM, which is expressed in Equation (6). In the case that the last data set is composed of linear combinations of the $k$ previous ones, the objective is to find $\theta_{i}$, which is a vector coefficient. The optimum weight $\theta_{i}$ is obtained as a solution of (6) and it can be found by minimizing the distance between the predicted outputs $\bar{X}$ from the measured results $x(t)$. With the help of Equation (7), it is possible to obtain the optimum weight $\theta_{i}$. With more data, it can be easier to see a convergence.

$$
\frac{d}{d \theta_{k}} \sum_{i=1}^{k}\|\bar{X}(t-i \Delta t)-x(t-i \Delta t)\|^{2}=0
$$

In this study, the improved dual ANN structure is proposed in order to obtain the parameters, which are related to one of the specific frequency regions. As in the previous study, theoretically the parameters of the equivalent circuit will be obtained from a pair of the battery voltage and current waveforms during its operation.

The internal voltage is expressed as a function of the SOC. The series resistor $R_{0}$ and the parallel $R_{1} C_{1}$ circuit in Figure 3 explain the voltage drop in a high frequency region and the other $R_{n} C_{n}$ circuit with the series capacitor $C_{\infty}$ expresses this in the low frequency region. The transient characteristic of the battery can be expressed by the circuit.

\subsection{Validating of the Improved Estimation Model}

Figure 14 shows the ANN structure where $\mathrm{U}$ and I are genuine and practical inputs obtained from the devices as illustrated in Appendix A, respectively Figures A1 and A2. Based on each frequency region the desired outputs are estimated, this is similar with the structure confirmed in [6], were the authors used Zre and Zim as the input of a single ANN structure.

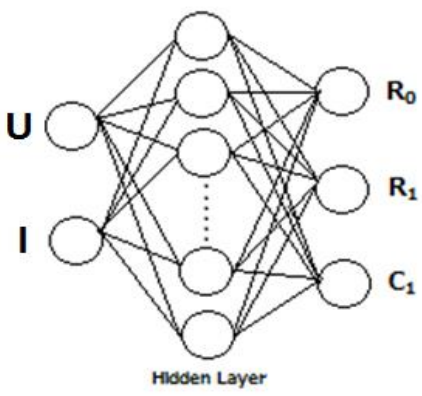

(a)

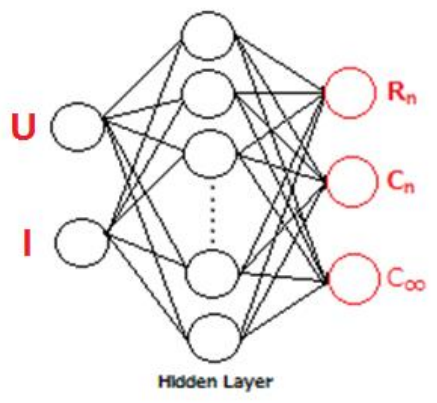

(b)

Figure 14. ANN structure for the proposed model: (a) structure used for high frequency region and (b) structure used for low frequency region.

Table 7 shows the results of the previous study for the wide regions of frequency. This was the most accurate case, especially based on the Li-Ion battery estimation.

Table 7. Estimated Circuit Parameters.

\begin{tabular}{ccc}
\hline Parameters & Measured & Estimated \\
\hline$R_{0}(\mathrm{~m} \Omega)$ & 48.3 & 46.65 \\
$R_{1}(\mathrm{~m} \Omega)$ & 2.3 & 2.46 \\
$R_{n}(\mathrm{~m} \Omega)$ & 58.2 & 56.35 \\
$C_{1}(\mathrm{kF})$ & 0.7 & 0.721 \\
$C_{n}(\mathrm{kF})$ & 1.88 & 1.81 \\
$C_{\infty}(\mathrm{MF})$ & 3.58 & 3.69 \\
\hline
\end{tabular}


The estimated cases are shown as below. It must be clarified that in this estimation the deterioration effect of the battery was inserted in order to be as much as possible a real case which includes the component of $\mathrm{SOH}$. In simple words, it means that an estimation model which includes a better generalization in deterioration was used. Tables $8-16$ show the results and comparison for each of 9 cases.

Table 8. Results of Case 1.

\begin{tabular}{ccc}
\hline Parameters & Measured & Estimated \\
\hline$R_{0}(\mathrm{~m} \Omega)$ & 47.9 & 55.18 \\
$R_{1}(\mathrm{~m} \Omega)$ & 2.4 & 2.81 \\
$R_{\mathrm{n}}(\mathrm{m} \Omega)$ & 57.5 & 67.85 \\
$C_{1}(\mathrm{kF})$ & 0.65 & 0.54 \\
$C_{n}(\mathrm{kF})$ & 1.9 & 1.61 \\
$C_{\infty}(\mathrm{MF})$ & 3.5 & 4.1 \\
\hline
\end{tabular}

Table 9. Results of Case 2.

\begin{tabular}{ccc}
\hline Parameters & Measured & Estimated \\
\hline$R_{0}(\mathrm{~m} \Omega)$ & 50.2 & 55.3 \\
$R_{1}(\mathrm{~m} \Omega)$ & 2.42 & 2.13 \\
$R_{n}(\mathrm{~m} \Omega)$ & 59.1 & 51.95 \\
$C_{1}(\mathrm{kF})$ & 0.75 & 0.65 \\
$C_{n}(\mathrm{kF})$ & 2.1 & 2.39 \\
$C_{\infty}(\mathrm{MF})$ & 3.74 & 4.13 \\
\hline
\end{tabular}

Table 10. Results of Case 3.

\begin{tabular}{ccc}
\hline Parameters & Measured & Estimated \\
\hline$R_{0}(\mathrm{~m} \Omega)$ & 50.8 & 57.09 \\
$R_{1}(\mathrm{~m} \Omega)$ & 2.46 & 2.12 \\
$R_{n}(\mathrm{~m} \Omega)$ & 58.1 & 52.11 \\
$C_{1}(\mathrm{kF})$ & 0.82 & 0.93 \\
$C_{n}(\mathrm{kF})$ & 1.9 & 1.65 \\
$C_{\infty}(\mathrm{MF})$ & 3.65 & 3.22 \\
\hline
\end{tabular}

Table 11. Results of Case 4.

\begin{tabular}{ccc}
\hline Parameters & Measured & Estimated \\
\hline$R_{0}(\mathrm{~m} \Omega)$ & 49.2 & 57.95 \\
$R_{1}(\mathrm{~m} \Omega)$ & 2.38 & 1.94 \\
$R_{n}(\mathrm{~m} \Omega)$ & 58.9 & 70.03 \\
$C_{1}(\mathrm{kF})$ & 0.85 & 1.02 \\
$C_{n}(\mathrm{kF})$ & 1.94 & 2.27 \\
$C_{\infty}(\mathrm{MF})$ & 3.62 & 3.04 \\
\hline
\end{tabular}

Table 12. Results of Case 5.

\begin{tabular}{ccc}
\hline Parameters & Measured & Estimated \\
\hline$R_{0}(\mathrm{~m} \Omega)$ & 51.3 & 47.7 \\
$R_{1}(\mathrm{~m} \Omega)$ & 2.43 & 2.22 \\
$R_{n}(\mathrm{~m} \Omega)$ & 59.7 & 64.17 \\
$C_{1}(\mathrm{kF})$ & 0.74 & 0.82 \\
$C_{n}(\mathrm{kF})$ & 1.95 & 2.15 \\
$C_{\infty}(\mathrm{MF})$ & 3.7 & 4.03 \\
\hline
\end{tabular}


Table 13. Results of Case 6.

\begin{tabular}{ccc}
\hline Parameters & Measured & Estimated \\
\hline$R_{0}(\mathrm{~m} \Omega)$ & 50.5 & 53.01 \\
$R_{1}(\mathrm{~m} \Omega)$ & 2.35 & 2.18 \\
$R_{n}(\mathrm{~m} \Omega)$ & 59.2 & 63.94 \\
$C_{1}(\mathrm{kF})$ & 0.78 & 0.84 \\
$C_{n}(\mathrm{kF})$ & 1.87 & 1.735 \\
$C_{\infty}(\mathrm{MF})$ & 3.72 & 4.01 \\
\hline
\end{tabular}

Table 14. Results of Case 7.

\begin{tabular}{ccc}
\hline Parameters & Measured & Estimated \\
\hline$R_{0}(\mathrm{~m} \Omega)$ & 48.9 & 50 \\
$R_{1}(\mathrm{~m} \Omega)$ & 2.32 & 2.45 \\
$R_{n}(\mathrm{~m} \Omega)$ & 58.9 & 60.7 \\
$C_{1}(\mathrm{kF})$ & 0.81 & 0.75 \\
$C_{n}(\mathrm{kF})$ & 1.92 & 1.81 \\
$C_{\infty}(\mathrm{MF})$ & 3.61 & 3.69 \\
\hline
\end{tabular}

Table 15. Results of Case 8.

\begin{tabular}{ccc}
\hline Parameters & Measured & Estimated \\
\hline$R_{0}(\mathrm{~m} \Omega)$ & 49.3 & 50.2 \\
$R_{1}(\mathrm{~m} \Omega)$ & 2.35 & 2.43 \\
$R_{n}(\mathrm{~m} \Omega)$ & 59.3 & 60.6 \\
$C_{1}(\mathrm{kF})$ & 0.85 & 0.87 \\
$C_{n}(\mathrm{kF})$ & 1.95 & 1.89 \\
$C_{\infty}(\mathrm{MF})$ & 3.65 & 3.72 \\
\hline
\end{tabular}

Table 16. Results of Case 9.

\begin{tabular}{ccc}
\hline Parameters & Measured & Estimated \\
\hline$R_{0}(\mathrm{~m} \Omega)$ & 48.3 & 46.65 \\
$R_{1}(\mathrm{~m} \Omega)$ & 2.3 & 2.46 \\
$R_{n}(\mathrm{~m} \Omega)$ & 58.2 & 56.35 \\
$C_{1}(\mathrm{kF})$ & 0.7 & 0.721 \\
$C_{n}(\mathrm{kF})$ & 1.88 & 1.81 \\
$C_{\infty}(\mathrm{MF})$ & 3.58 & 3.69 \\
\hline
\end{tabular}

Based on the estimated values for 9 cases, Figure 15 shows the absolute error values for each case. For each case of frequency regions, two columns are used to explain the minimum and maximum errors. In order to have a better generalization, the model has to also be aware of the different levels of deterioration. For each of the cases, the numbers are different because all the measure was made at different cycles of usage.

It is clear that even in Figure 16, the cases 7-9 achieve the lowest error. For $R_{0}, R_{n}, C_{\infty}$, the cases 7 and 8 have almost the same accuracy, which means that if you want to estimate the $\mathrm{SOH}$, we recommend to use the transient characteristics in case 7 in order to have less frequency points compared to the cases 8 or 9 . However, if the researchers want to focus in the $R_{1}, C_{1}$ and $C_{2}$, the case 8 is better compared to the case 7 or 9 . Based on the same technique on the Li-Ion, the estimation was achieved for the $\mathrm{Pb}$ and $\mathrm{Ni}-\mathrm{MH}$ batteries. 


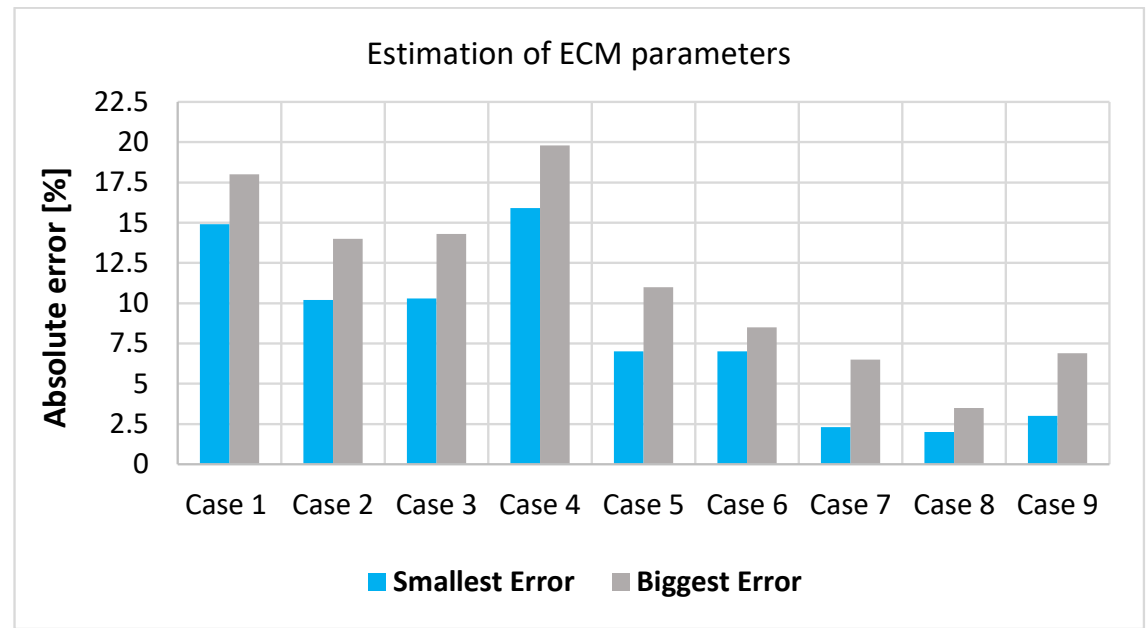

Figure 15. Error plot of Li-Ion battery for each frequency regions.

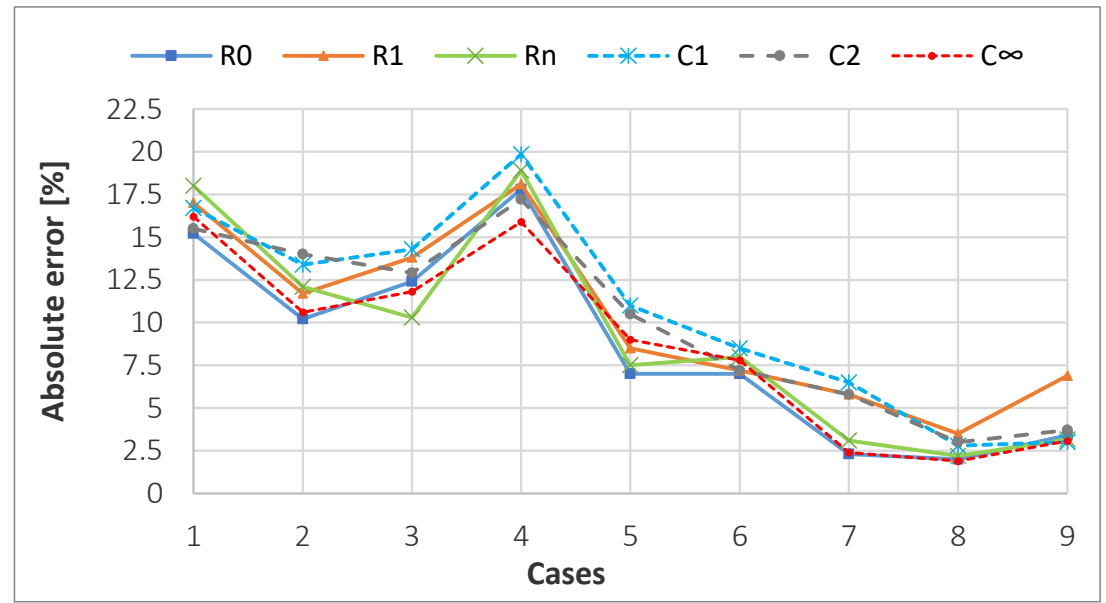

Figure 16. Error plot of Li-Ion battery for each of the parameters.

The measured data were obtained during SOC $100 \%$ for all the batteries, more details are illustrated in Appendix A, Figures A3-A6. In case of the Pb battery 0 cycle, 100 cycles, 200 cycles, 300 cycles, 500 cycles and 600 cycles information were used for the training process of the Dual ANN structure, which in comparison with the previous study was made until 300 cycles. Tables 17 and 18 show the best estimation case of frequency regions, which emphasize Case 4 and 5 with respective frequency:

Case 4-LF(10 mHz-1 Hz)/HF(10 Hz-100 Hz), Case 5-LF(10 mHz-1 Hz)/HF(10 Hz-1 kHz).

Table 17. Results of Case 4 for $\mathrm{Pb}$.

\begin{tabular}{ccc}
\hline Parameters & Measured & Estimated \\
\hline$R_{0}(\mathrm{~m} \Omega)$ & 60.5 & 57.96 \\
$R_{1}(\Omega)$ & 12.72 & 2.12 \\
$R_{n}(\mathrm{~m} \Omega)$ & 51 & 47.43 \\
$C_{1}(\mathrm{kF})$ & 2.5 & 2.605 \\
$C_{n}(\mathrm{kF})$ & 5.2 & 5.47 \\
$C_{\infty}(\mathrm{MF})$ & 4.7 & 4.97 \\
\hline
\end{tabular}


Table 18. Results of Case 5 for $\mathrm{Pb}$.

\begin{tabular}{ccc}
\hline Parameters & Measured & Estimated \\
\hline$R_{0}(\mathrm{~m} \Omega)$ & 61.3 & 65.1 \\
$R_{1}(\mathrm{~m} \Omega)$ & 11.95 & 12.77 \\
$R_{n}(\mathrm{~m} \Omega)$ & 53.2 & 50.38 \\
$C_{1}(\mathrm{kF})$ & 2.45 & 2.27 \\
$C_{n}(\mathrm{kF})$ & 5.36 & 5.745 \\
$C_{\infty}(\mathrm{MF})$ & 4.85 & 5.15 \\
\hline
\end{tabular}

Figure 17 shows the error value for each of the parameters regarding Cases 4-5.

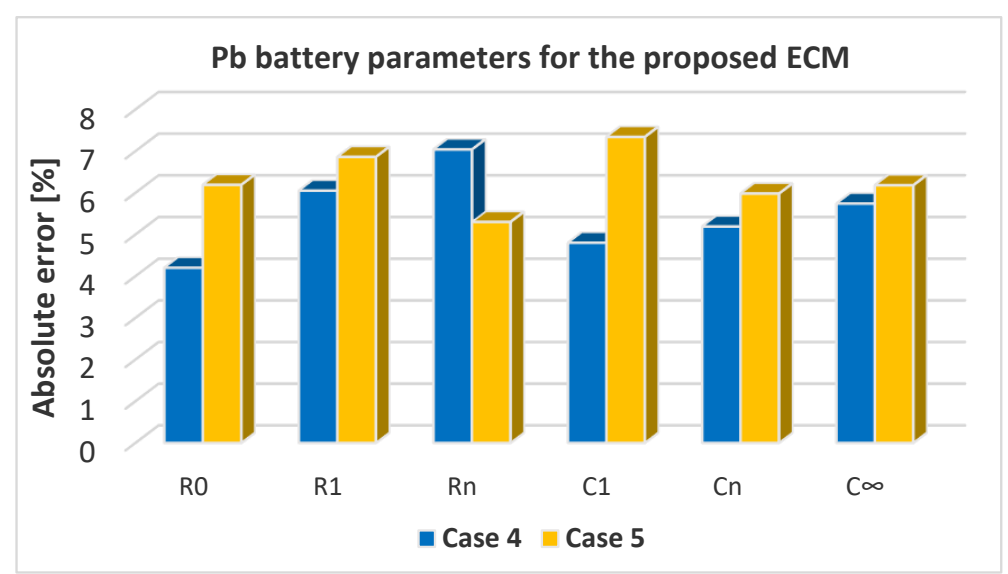

Figure 17. Error plot of $\mathrm{Pb}$ battery plot for each of the parameters.

Figure 18 show the estimation error plot of Ni-MH battery for the parameters. Case 6 in Table 19 and case 9 in Table 20 show the best estimation and generalization ability during all the estimation process.

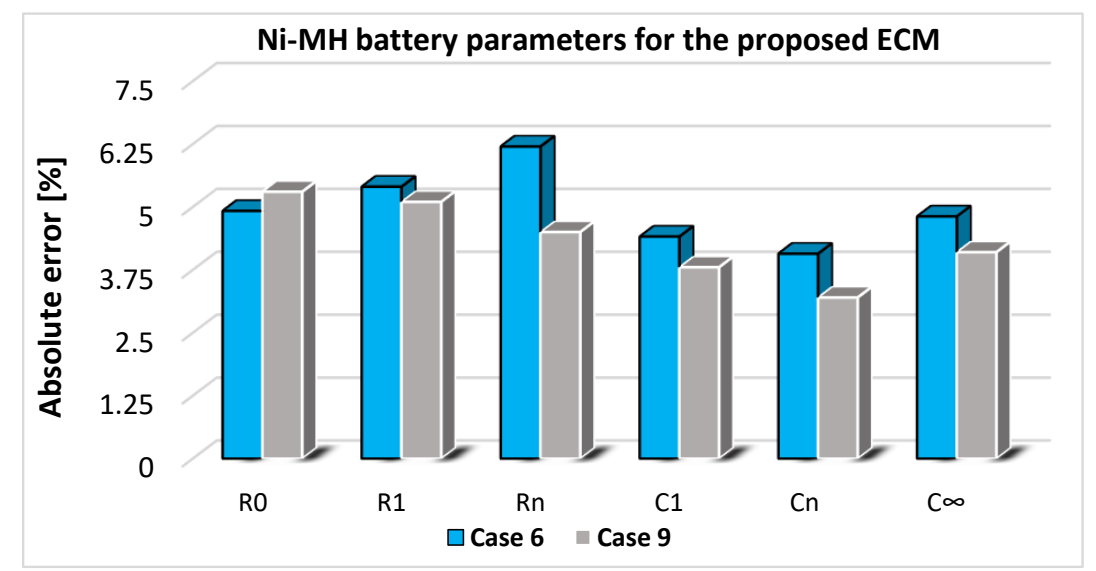

Figure 18. Error plot of Ni-MH battery for each of the parameters.

Table 19. Results of Case 6 for Ni-MH.

\begin{tabular}{ccc}
\hline Parameters & Measured & Estimated \\
\hline$R_{0}(\mathrm{~m} \Omega)$ & 26.4 & 25.1 \\
$R_{1}(\mathrm{~m} \Omega)$ & 5.9 & 6.22 \\
$R_{n}(\mathrm{~m} \Omega)$ & 32.4 & 30.39 \\
$C_{1}(\mathrm{kF})$ & 0.68 & 0.71 \\
$C_{n}(\mathrm{kF})$ & 2.092 & 2.092 \\
$C_{\infty}(\mathrm{MF})$ & 3.76 & 3.76 \\
\hline
\end{tabular}


Table 20. Results of Case 9 for Ni-MH.

\begin{tabular}{ccc}
\hline Parameters & Measured & Estimated \\
\hline$R_{0}(\mathrm{~m} \Omega)$ & 28.2 & 29.69 \\
$R_{1}(\mathrm{~m} \Omega)$ & 5.1 & 4.83 \\
$R_{n}(\mathrm{~m} \Omega)$ & 34.1 & 32.56 \\
$C_{1}(\mathrm{kF})$ & 0.71 & 0.73 \\
$C_{n}(\mathrm{kF})$ & 2.16 & 2.09 \\
$C_{\infty}(\mathrm{MF})$ & 3.89 & 4.05 \\
\hline
\end{tabular}

Respectively, the frequency regions of the 2 cases for Ni-MH battery are shown as below:

\section{Case6-LF(10 mHz-1 Hz)/HF(10 Hz-10 kHz), Case 9-LF(10 mHz-10 Hz)/HF(10 Hz-10 kHz).}

Figure 19 shows the optimal frequency region depending on the type of battery based on the matrix plot. Each battery is colored differently in order to distinguish the type. As explained above, the optimal cases are 4 and 5 for the $\mathrm{Pb}$ battery, which has a LF range from $10 \mathrm{mHz}$ to $1 \mathrm{~Hz}$ and a HF range of up to $1 \mathrm{kHz}$. For Ni-MH, the best cases are 6 and 9, which shows the fact that this battery is highly dependent in the extreme regions of HF up to $10 \mathrm{kHz}$ and LF up to $10 \mathrm{~Hz}$. Regarding the Li-Ion, the best cases are 7 and 8 . At the same time, the case 9 can be used if the user can accept errors of up to $6.7 \%$. Furthermore, the case 9 shows good generalization. However, we recommend the cases 7 and 8 for the optimal estimation with a LF of up to $10 \mathrm{~Hz}$ and a HF with a maximum frequency of $1 \mathrm{kHz}$ or $10 \mathrm{kHz}$ for the case 9 frequency specified in Table 5.

Figure 20 provides a simpler explanation derived from the matrix characteristics in Figure 19. This plot specify which frequency must be used in order to obtain a better estimation. For example, the $\mathrm{Pb}$ battery is recommended to be used in the LF region of up to $1 \mathrm{~Hz}$ but it can be used in a HF region from $10 \mathrm{~Hz}$ to $100 \mathrm{~Hz}$ or even up to $1 \mathrm{kHz}$. Thus, in the $\mathrm{HF}$ region, 1 decade or 2 decades can be used. If the user needs more accuracy, the data set must be studied in a frequency range with a maximum of $1 \mathrm{kHz}$ but they must be aware that this higher frequency requires more data points, more calculation time and experiments. Thus, this needs more powerful hardware to handle the processing. In addition, in the case of the embedded circuit, the computational power is very important as less data will make it faster for the circuit in order to handle it. Thus, depending on the type of the application, cost, accuracy and time, the user can choose the best regions among the recommended by the authors. The cost/performance trade-off must be taken into account.

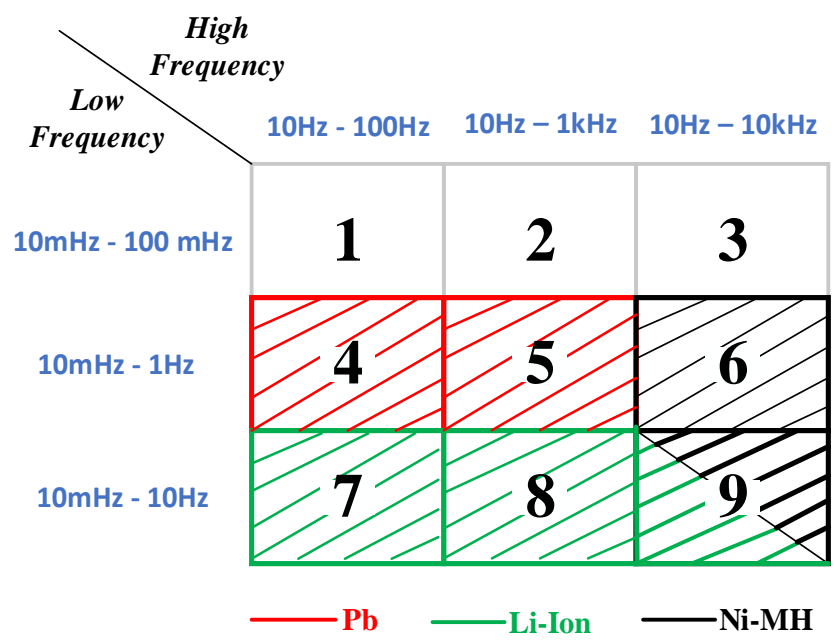

Figure 19. Matrix characteristics for the optimal frequency region depending on the type of battery. 


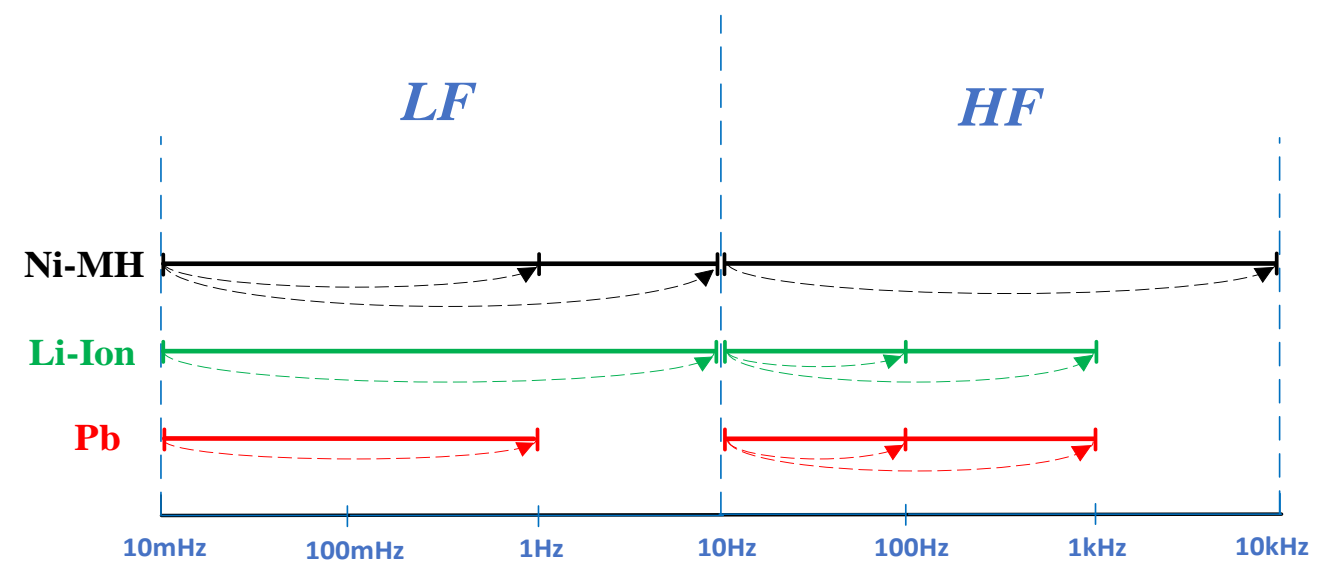

Figure 20. Optimal Frequency Bandwidth for each battery type.

\section{Conclusions}

In this study, the updated and improved version of the dual ANN structure for estimating the circuit parameters of the rechargeable batteries was introduced. As already explained in the previous study [13-15], due to the difficulty to handle a wide range of frequency, the estimation process was divided into a high-frequency region, which is related with the maximum chargeable/dischargeable current, and a low-frequency region, which is closely related with $\mathrm{SOH}$. With the help of ANNs, it was possible to estimate these variables with a small difference between the real and calculated by NN and processed in MATLAB R2018a. The updated algorithm with better estimation and calculation time, adaptive algorithm for a better generalization made possible even for different regions of frequency to estimate with high accuracy. In this study, the number of cycles was increased in order to make possible to study the batteries at the full range of deterioration from a new to totally deteriorated based on the manufacture's datasheet. In addition, this fact helps to increase the generalization of the method and it can be used for future diagnosis work, related to the $\mathrm{SOH}$ fade. As well the range of discharging ratio was increased, $0.1 \mathrm{C}, 0.2 \mathrm{C}, 0.5 \mathrm{C}, 0.6 \mathrm{C}, 0.8 \mathrm{C}$ and $1 \mathrm{C}$. It was possible to obtain an accurate estimation with $2 \%$ error for the Li-Ion for frequency from $10 \mathrm{mHz}$ up to $1 \mathrm{kHz}$, an estimation error of $3.3 \%$ for $\mathrm{Ni}-\mathrm{MH}$ especially for high frequency regions up to $10 \mathrm{kHz}$ and a minimum error of $4.1 \%$ for $\mathrm{Pb}$ battery which is based mostly in low frequency regions, with frequency up to $100 \mathrm{~Hz}$ or $1 \mathrm{kHz}$ in case that a large number of data points can be obtained. The frequency points were maintained constant the same as in the previous study to confirm the model in case of a small amount of data. In the final step after optimizing and improving the algorithm and the structure of the ANN, the required inputs cells are less than 100, depending by the battery type, capacity, and the charging/discharging ratio. The number of neurons was changed a little comparing from the previous work, as in the hidden layer for the high-frequency structure 32 neurons and in the low-frequency region is 28 neurons. Through this study, it was possible to investigate further the relation of the frequency regions with parameters value of the proposed ECM. The accuracy and generalization were improved as shown in Appendix A, Table A1. The estimation was calculated in just a few seconds. The future work will be the focus on obtaining a more reliable and accurate model from a practical device during dynamic loads. As well using parameters like OCV waveform and capacity fade, as online-adaptive parameter approach with the help of ANN [22-27], based on an arbitrary waveform will be investigated for the real-time diagnosis.

Author Contributions: M.B. developed the MATLAB code for the ANN algorithm with a generalization characteristic, conducted all the battery experiments by the devices which are in shown in Appendix A respectively NF As-510-LBA, AS-510-B shown in Figure A1 and Thermo-hygrostat HIFLEX KEYLESS TL401E as shown in Figure A2, and also wrote most of the manuscripts. R.G. conducted most of the experiments in the proposed multi-type secondary-battery circuit, with CCCV mode and by pulse waveform as well did some data analysis. N.N. supervised all process of the development, experiments and results, also checked the whole manuscript.

Funding: This research received no external funding. 
Acknowledgments: The author would like to thank you the Battery Team of the Power System Analysis Lab. for their support especially T. Ishii, K. Iifuru and K. Toyooka, who are graduated from Doshisha University in 2018, for their support of retrieving specific data necessary for this project.

Conflicts of Interest: The authors declare no conflict of interest.

\section{Appendix A}

Figures A1 and A2 show the devices used to obtain the experimental data used for the training of the ANN.

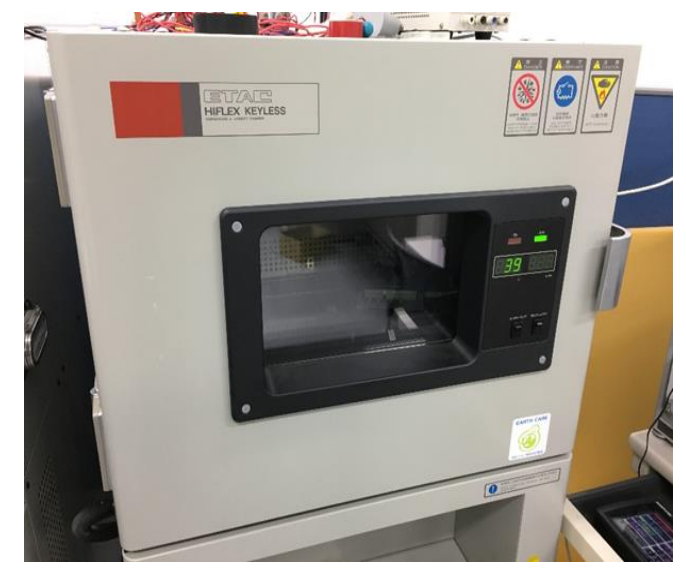

Figure A1. Thermo-hygrostat (HIFLEX KEYFLESS TL401E).

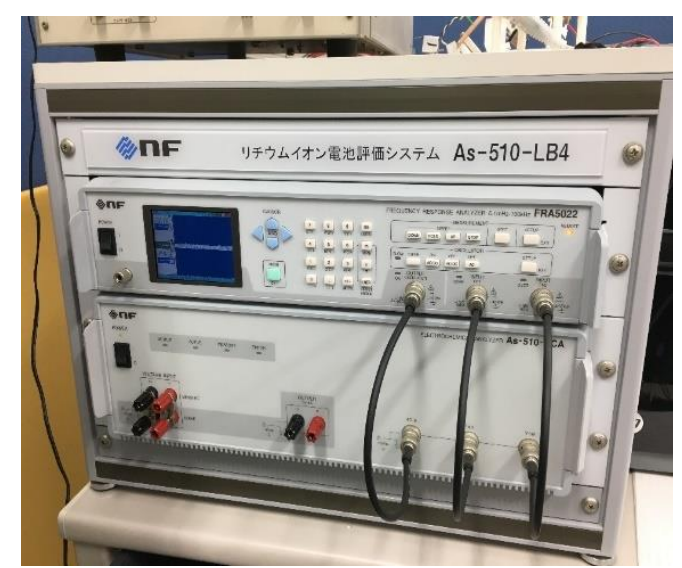

Figure A2. Evaluation system AS-510-LB4.

As already explained in the Author Contributions, most of the data were obtained by these devices, but in the same time extra data were obtained through the multi-type Secondary-Battery Charger/Discharger by Arbitrary Current Waveform [16]. From this device extra experiments were conducted for waveforms different from $\mathrm{CCCV}$ mode, pulse current where used. Also, different charging/discharging ratio was conducted as: $0.1 \mathrm{C}, 0.2 \mathrm{C}, 0.3 \mathrm{C}, 0.5 \mathrm{C}, 0.8 \mathrm{C}, 1 \mathrm{C}$, as shown in Figure $\mathrm{A} 3$. The range of the experiments where conducted from a new battery to a full deteriorated as specified in the official specification, from 0 cycle to (500-600) cycle. Figure A3 shows the discharging plot for different ratio.

Figure A4 shows Cole-Cole plot during the charging process. All the values of the ECM parameters are extracted at $100 \%$ SOC. The authors would like to investigate further the effect of ratio in the deterioration effect of the batteries related to the values of the internal resistance. Temperature as well-known variable which reduce the lifetime of the battery, should be inserted in the nonlinear characteristics. Also, other experiments based on the pulse waveform are conducted by the authors, 
in future works these experiments will compare the effect of the pulse charging or any arbitrary waveform for a practical application in EV batteries.

Table A1. Comparison of accuracy between previous and this study.

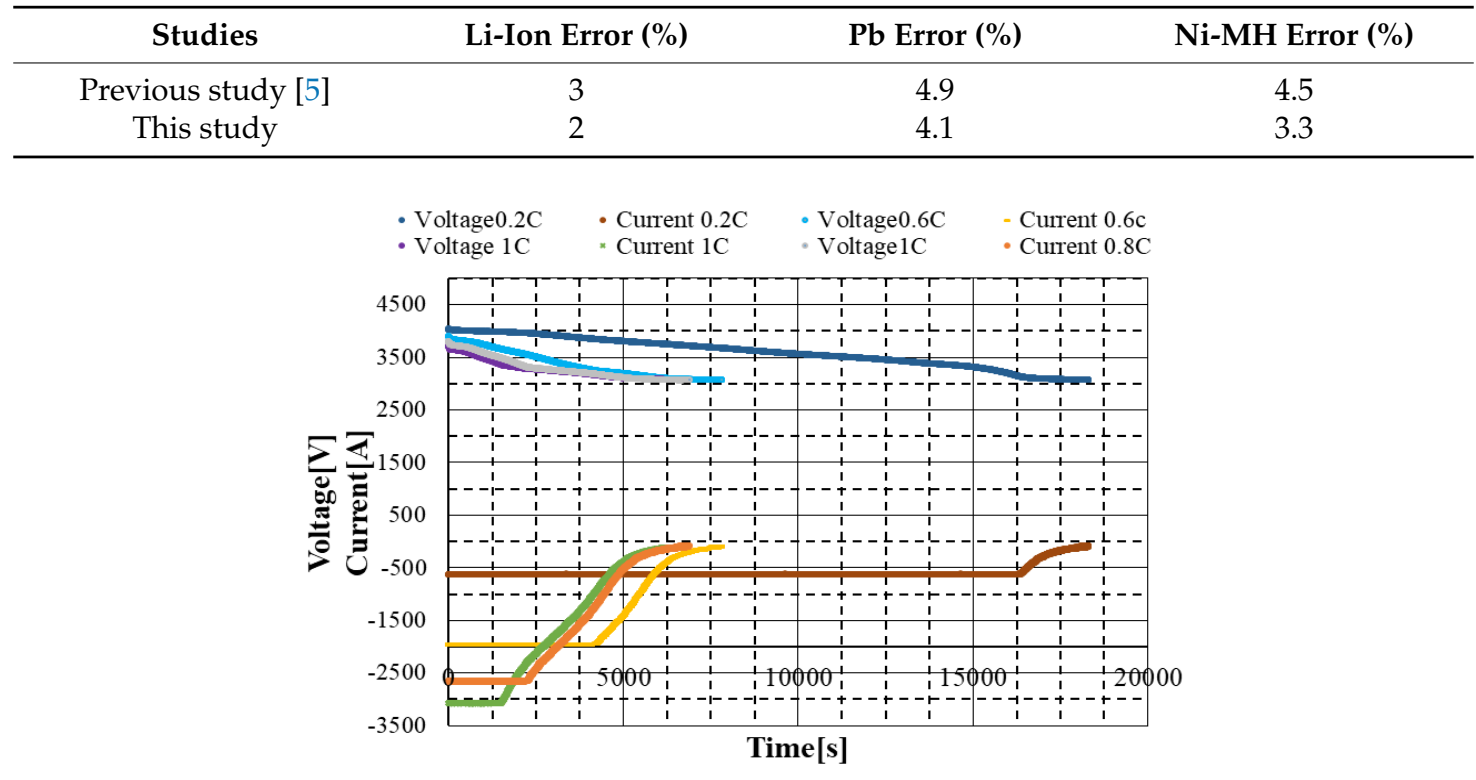

Figure A3. Cole-Cole plot of the li-ion battery.

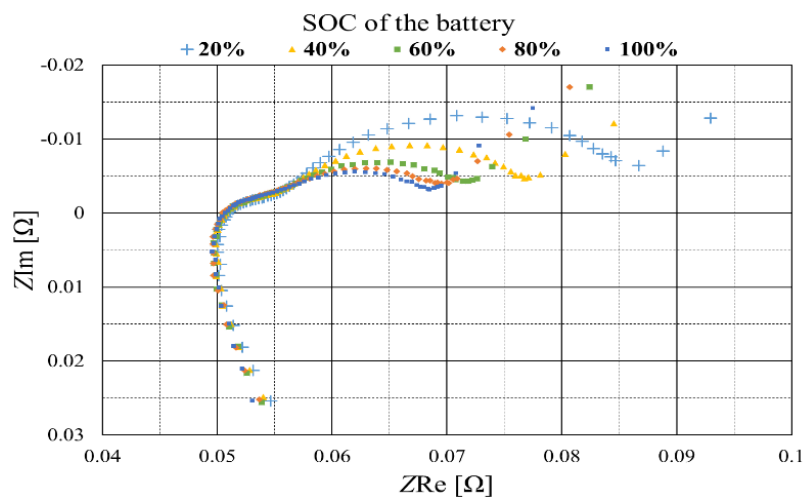

Figure A4. Cole-Cole plot of the li-ion battery in different SOC.

Figures A5 and A6 respectively shows the genuine data obtained through experiments and that one estimated from the test, which was used in the training process of the ANN.

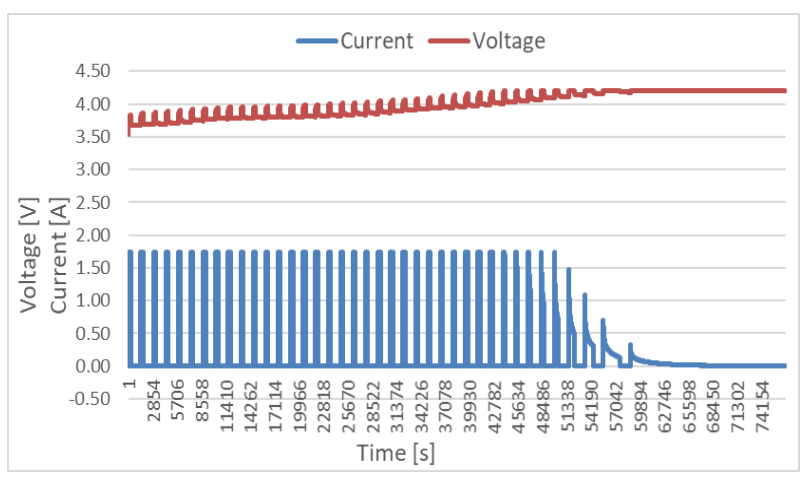

Figure A5. Experimental Voltage \& Current waveforms. 


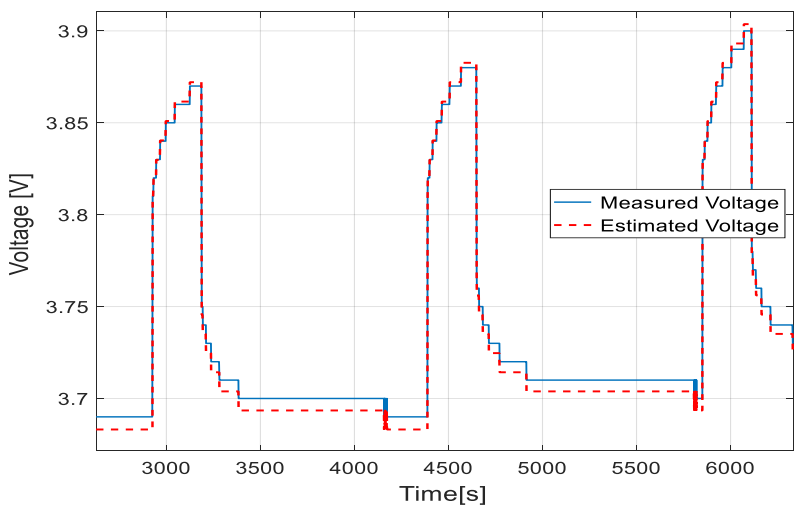

Figure A6. Zoomed image of the estimated test voltage.

\section{References}

1. Nagaoka, N.; Ametani, A. An Estimation Method of Li-Ion Battery Impedance Using Z-Transform. In Proceedings of the 2012 IEEE 13th Workshop on Control and Modeling for Power Electronics (COMPEL), Kyoto, Japan, 10-13 June 2012.

2. Hirai, T.; Ohnishi, A.; Nagaoka, N.; Mori, N.; Ametani, A.; Umeda, S. Automatic Equivalent-Circuit Estimation System for Lithium-Ion Battery. In Proceedings of the 43rd International University Power Engineering Conference, Padova, Italy, 1-4 September 2008.

3. Vetter, J.; Novak, P.; Wagner, M.R.; Veit, C.; Moller, K.-C.; Besengard, J.O.; Winter, M.; Wohlfahrt, M.; Vogler, C.; Hammouche, A. Ageing mechanisms in lithium-ion batteries. J. Power Sour. 2005, 147, $269-281$. [CrossRef]

4. Nagaoka, N. A Numerical Model of Lithium-Ion Battery for a Life Estimation. In Proceedings of the 2013 48th International Universities Power Engineering Conference (UPEC), Dublin, Ireland, 2-5 September 2013.

5. Bezha, M.; Gondo, R.; Nagaoka, N. A Dual ANN Model for Estimation of Internal Impedance of Rechargeable Cell Battery. In Proceedings of the Universities Power Engineering Conference (UPEC) 2018 53rd International, Glasgow, UK, 4-7 September 2018; pp. 1-6.

6. Bezha, M.; Nagaoka, N. An ANN Model for Estimating Internal Impedance of Lithium-Ion Battery Cell for Industrial Application. In Proceedings of the 2018 21st International Conference on Electrical Machines and Systems (ICEMS), Jeju, Korea, 7-10 October 2018; pp. 2105-2110.

7. Klein, R.; Chaturvedi, N.A.; Christensen, J.; Ahmed, J.; Findeisen, R.; Kojic, A. Electrochemical Model Based Observer Design for a Lithium-Ion Battery. IEEE Trans. Control Syst. Technol. 2013, 21, 289-301. [CrossRef]

8. Srinivasan, V.; Wang, C. Analysis of Electrochemical and Thermal Behavior of Li-Ion Cells. J. Electrochem. Soc. 2003, 150, 98-106. [CrossRef]

9. Nyman, A.; Zavalis, T.G.; Elger, R.; Behm, M.; Lindbergh, G. Analysis of the Polarization in a Li-Ion Battery Cell by Numerical Simulations. J. Electrochem. Soc. 2010, 157, 1236-1246. [CrossRef]

10. Doyle, M.; Newman, J. The use of mathematical modeling in the design of lithium/polymer battery systems. Electrochim. Acta 1995, 40, 2191-2196. [CrossRef]

11. Dao, T.S.; Schmitke, C. Developing Mathematical Models of Batteries in Modelica for Energy Storage Applications. In Proceedings of the 11th International Modelica Conference, Versailles, France, 21-23 September 2015; pp. 469-477.

12. Lam, L.; Bauer, P.; Kelder, E. A practical circuit-based model for li-ion battery cells in electric vehicle applications. In Proceedings of the IEEE 33rd International Telecommunication Energy Conference (INTELEC), Amsterdam, The Netherlands, 9-13 October 2011; pp. 1-9.

13. Takano, K.; Nozaki, K.; Saito, Y.; Negishi, A.; Kato, K.; Yamaguchi, Y. Simulation study of electrical dynamic characteristics of Lithium-Ion battery. J. Power Sour. 2000, 90, 214-223. [CrossRef]

14. Noro, T.; Narita, N.; Higo, T.; Nagaoka, N. A Deterioration Diagnosis Method for Lithium-Ion Battery Based on Phase characteristics of Internal Impedance. In Proceedings of the University Power Engineering Conference 50th International, Staffordshire, UK, 1-4 September 2015. 
15. Ishii, T.; Nagaoka, N. A logarithmic segmented Laplace transform and its application to a battery diagnosis. In Proceedings of the UPEC 52nd International Universities Power Engineering Conference, Crete, Greece, 28-31 August 2017; pp. 949-953.

16. Ametani, A.; Imanishi, K. Development of exponential Fourier transform and its application to electrical transients. Proc. IEE 1979, 126, 51-56. [CrossRef]

17. Ametani, A.; Yamaoka, S. On logarithmic Fourier transform. In Proceedings of the IEE Japan Research Committee of Information Processing, Special Technical Report IP-77-17 Archives, Tokyo, Japan, 1977.

18. Gondo, R.; Ito, S.; Iifuru, K.; Nagaoka, N. Development of Multi-Type Secondary-Battery Charger/Discharger by Arbitrary Current Waveform. In Proceedings of the 52nd International Universities' Power Engineering Conference, Crete, Greece, 28-31 August 2017.

19. Yang, S.; Deng, C.; Zhang, Y.; He, Y. State of Charge Estimation for Lithium-Ion Battery with a Temperature-Compensated Model. Energies 2017, 10, 1560. [CrossRef]

20. Chim, C.S.; Gao, Z. State-of-Charge Estimation of Battery Pack under Varying Ambient Temperature Using an Adaptive Sequential Extreme Learning Machine. J. Energies 2018, 11, 771800.

21. Bezha, M.; Nagaoka, N. An ANN for Estimation of Power Consumption of EV/HEV for Real Time Battery Diagnosis. In Proceedings of the IEEJ SAMCON2018, Tokyo, Japan, 6-8 March 2018.

22. Fleischer, C.; Waag, W.; Heyn, H.-M.; Sauer, D.U. On-line adaptive battery impedance parameter and state estimation considering physical principles in reduced order equivalent circuit battery models part 2. Parameter and state estimation. J. Power Sour. 2014, 262, 457-482. [CrossRef]

23. Hussein, A.A. Capacity Fade Estimation in Electric Vehicle Li-Ion batteries using Artificial Neural Networks. IEEE Trans. Ind. Appl. 2015, 51, 2321-2330. [CrossRef]

24. Bezha, M.; Nagaoka, N. Predicting Voltage Characteristic of Charging Model for Li-Ion Battery with ANN for Real time Diagnosis. In Proceedings of the IPEC ECCE ASIA IEEE, Niigata, Japan, 20-24 May 2018.

25. Stroe, D.; Swierczynski, M.; Stroe, A.; Kaeer, S.K.; Teodorescu, R. Lithium-ion battery power degradation modelling by electrochemical impedance spectroscopy. J. IET Renew. Power Gener. 2017, 11, 1136-1141. [CrossRef]

26. Guha, A.; Patra, A. State of Health Estimation of Lithium-Ion Batteries Using Capacity Fade and Internal Resistance Growth Models. IEEE Trans. Transp. Electrif. 2018, 4, 135-146. [CrossRef]

27. Somakettarin, N.; Funaki, T. Study on Factors for Accurate Open Circuit Voltage Characterizations in Mn-Type Li-Ion Batteries. Artic. Batter. 2017, 3, 8. [CrossRef] 